\title{
SOURCES AND MECHANISMS OF RESISTANCE TO SORGHUM HEAD BUG, EURYSTYIUS IMMACULATUS ODH. IN WEST AFRICA
}

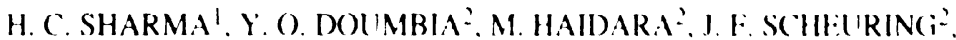 \\ K. V. RAMAIAH' and N. F. BENINAT'? \\ International (rops Research Institute for the Semi-Ard Tropues (IC RISAR). \\ Patancheru. A.P. 5(12 324. Indai: \\ institut deconomic Rurale. Station de Recherches sur les ('ultures Vivereres \\ et Oleaguneuse, B.P. 438, Sutuba, Mall. \\ 'West African Sorghum Improvement Program, IC RISAT. Bamahu, Malı
}

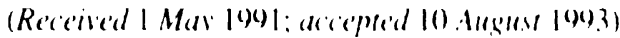

\begin{abstract}
Sorghum is one of the most important cereal crops in West Africa, and the head bug, Eurystylus immaculatus ()dh. (Hemiptera: Miridae) is the key pest of grain sorghum in this region. A range of sorghum genotypes were evaluated for resistance to sorghum head bug at Sotuba (Mali) and Kamboinse (Burkina Faso). (ienotypes CSM 388. IS 143.32. Malisor 84-7. Sakoika, S 29 and Kamboinse local were resistant to head bugs, both under natural and headcage screening. Head bug resistant genotypes had a lower percentage of head bug damaged grain. The food quality of head bug damaged grain was very poor and unacceptable.

Cultivar non-preference was identified as a component of resistance to head bugs, and ( SM .388 was nonpreferred compared to $\mathbf{E}$ 35-1. Panicle compactness was positively associated with head bug numbers and grain damage. However, genotypes with loose panicles were also susceptible to bugs. Long glumes ( $>5 \mathrm{~mm}$ ), days to glume opening ( $>20$ days after anthesis), $>50 \%$ covering of the grain by the glumes, and grain hardness contribute towards resistance to Eurystylus immaculatus. This information will be useful for developing a programme to breed for resistance to this insect in West Africa.
\end{abstract}

Key Words: Eurystylus immaculatus, Miridae, sorghum, host-plant resistance, mechamsmo of ressutance, head bugs

Résumé-Divers génotypes de sorgho ont été évalués pour la résistance à la punaise des panicules du sorgho, Eurystylus immaculatus (Odh. à Sotuha (Mali) et a Kamboinsé (Burkina Faso). Lés génotypes CSM 388, IS 14332, Malisor 84-7. Sakoika, S 29 et Kaınboinsé local étaient relativement résistants aux punaises en criblage naturel ou en cage. Les génotypes résistants à la punaise avaient un pour centage moins élevé de graines endommagées par les punaises. La qualité alimentaire des graines endommagées était trés faible et inacceptable.

La non préférence des cultivars était identifiée comme une composante de la résistance aux punaises. Le CSM 388 était non préféré par rapport au E. 35-I. I a densité de la panicule était positivement associée avec les nombres de punaises et les dégâts aux graines. Cependant, les génotypes avec des panicules lâches étaient également susceptibles aux punaises. I.es glumes longues ( $>5 \mathrm{~mm}$ ), le nombre de jours à l'ouverture des glumes ( $>20$ jours après l'anthese), $>50 \%$ de couverture de la graine par les glumes, ainsi que la dureté de la graine contribuent à la résistance à Eurystylus. 


\section{ETol Afroduction}

Sorghum, Sorghum bicolor (L.) Moench is an important cereal crop in West Africa, and insect pests are among the major factors limiting production (Nwanze, 1985). Over 100 species of insects have been reported as serious pests of sorghum in the Sahel, of which the mirid head bug, Eurystylus immaculatus Odh. is a key pest (McFarlane, 1989; Sharma et al., 1992; Doumbia and Bonzi, 1985).

Efforts to breed and introduce medium maturity high yielding cultivars into West Africa have largely been unsuccessful, because of head bug damage, which adversely affects the grain quality, and renders the grain unfit for food preparations such as "to" (a thick porridge prepared from sorghum flour) and "Cous-Cous". Hard and vitreous grain is preferred for these food preparations, while head bug damage renders the grain soft and starchy. Head bug eggs are laid inside the developing grain and the oviposition site turns red-to-black due to decomposition of starch and accumulation of tannins. This changes the colour of food preparations. Head bug damage also leads to greater incidence of grain moulds (Sharma et al., 1992), which adversely affect the appearance and germination of the grain as well as food quality.

Crop improvement efforts in the sub-Sahelian zone, therefore, need to focus on developing cultivars less susceptible to head bugs. There is no available information on host plant resistance to this insect. The present studies were therefore undertaken to identify sources of resistance, and understand the factors associated with resistance to $E$. immaculatus in sorghum.

\section{MATERIALS AND METHODS}

\section{Screening for resistance}

Cultivar susceptibility to head bugs was evaluated in 11 cultivars at Sotuba, Mali during the 1985 rainy season. There were three replications in a randomized complete block design. The crop was planted on ridges $75 \mathrm{~cm}$ apart, and the seedlings were thinned to a $10-\mathrm{cm}$ spacing within the row, 15 days after emergence. Plot size was $4 \times 3 \mathrm{~m}$. Normal agronomic practices were followed for raising the crop. No insecticide was applied during the reproductive phase of the crop.

Five randomly marked panicles were screened for head bug resistance in each genotype under nochoice conditions in a headcage (Sharma et al., 1992). Each panicle was infested with 20 pairs of bugs at the milk stage i.e., 12 days after anthesis. Head bug numbers in the infested panicles were recorded 20 days after infestation. The panicles were rated for head bug damage at maturity on a 1 to 5 scale $(1=$ grain with a few feeding punctures; and $5=$ grain showing $>60 \%$ shrivelling and discoloration to brownish-red) (Sharma et al., 1992). Head bug numbers under natural infestation in different genotypes were recorded in five panicles sampled at random in a polyethylene bag $(45 \times 30 \mathrm{~cm})$ at the dough stage as described by Sharma and Lopez (1992a). Cultivars were also evaluated for grain damage by the bugs at maturity on a 1 to 5 scale as described before.

Data were also recorded on 1000 grain weight of light and heavy grain separated in sodium nitrate solution with a specific density of 1.31 (Hallgren and Murty, 1983), \% light grain, grain hardness ( 1 = grain hard and corneous, and $5=$ grain soft and floury); and "to" quality ( 1 = "to" light-olive and granular, and 5 = "to" dark-brown in colour and pasty) (Da et al., 1982).

During the 1988 rainy season, four cultivars were evaluated for resistance to head bugs under natural and headcage conditions at Sotuba and Samanko, Mali. Each plot measured $6 \times 9 \mathrm{~m}$. There were three replications in a randomized complete block design. Normal agronomic practices were followed for raising the crop as described before. Head bug numbers under natural conditions were recorded in five panicles sampled at random in each replication. Cultivars were also screened in a headcage using 20 pairs of adults or 100 third-instar nymphs/panicle at the complete-anthesis stage. Head bug numbers in the cages were counted 20 days after infestation. Panicles were rated for grain damage at maturity as described before. Data were also recorded on 1000 grain weight and seed germination as described earlier (Sharma et al., 1992).

During the 1986 rainy season, four cultivars were evaluated for head bug resistance under headcage at Kamboinse, Burkina Faso. Normal agronomic practices were followed for raising the crop. No insecticide was applied during the reproductive phase of crop. Each plot measured $4 \times 3 \mathrm{~m}$, and there were three replications in a randomized complete block design. Five randomly marked panicles were caged with 20 pairs of bugs/panicle at the complete-anthesis stage in each cultivar. Head bug numbers in the infested panicles were recorded 20 days after infestation. Panicles were rated for grain damage at maturity as described before.

\section{Mechanisms of resistance}

Non-preference. Cultivar preference by adult bugs was studied both under field and laboratory conditions 


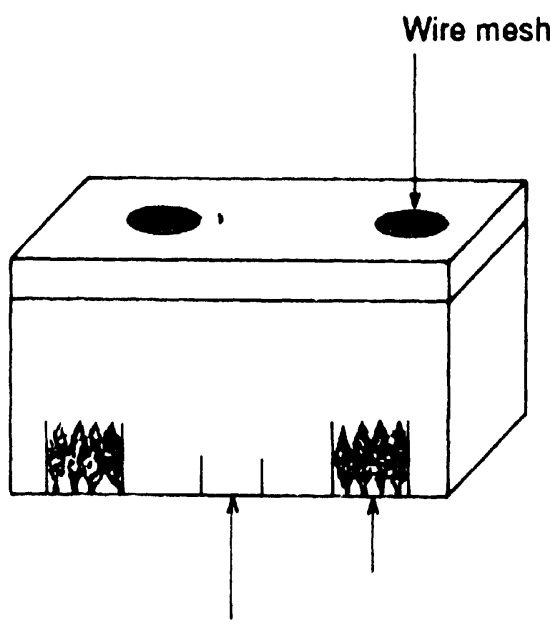

Head bug vial

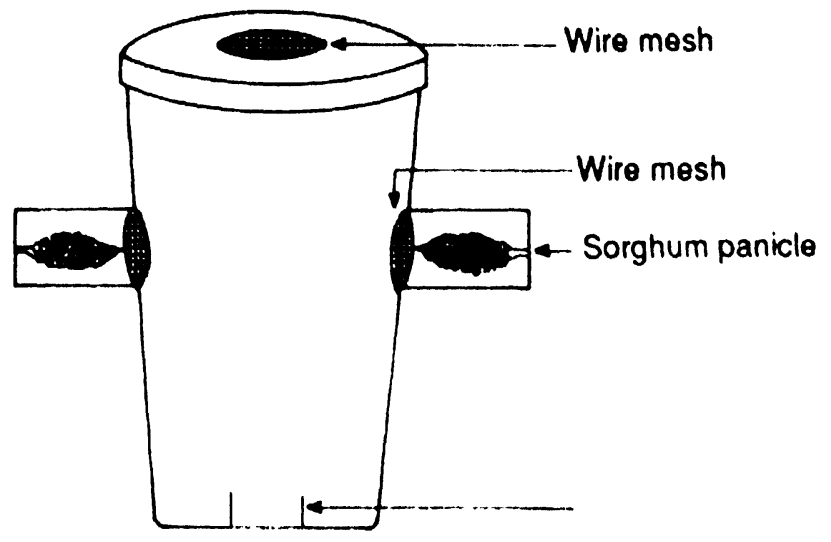

Fig. 1. Olfactometers to study cultivar preference of sorghum head bug with $(A)$ and without (B) contact with the host plant.

during the 1985 rainy season at Sotuba. Under field conditions, the number of bugs attracted to the panicles of different genotypes for feeding and oviposition were recorded at the early milk stage i.e.. 12 days after anthesis. Five panicles were randomly sampled individually in a polyethylene bag as described before. The number of bugs recorded on each genotype was taken as a measure of genotypic preference hy the head bugs.

Under laboratory conditions, cultivar nonpreference by the adults was studied through olfactometer tests, which allowed the orientation of head bugs to be monitored with and without contact with the host plant (Fig. 1). Three cultivars were evaluated for relative preference as described above. Milk grains of the susceptible cultivar, E 35-1 were used as a standard check. Twenty bugs were released in the centre of the olfactometer. The number of bugs (\% of the total released) responding to each genotype was recorded after $4 \mathrm{hr}$. The experiment was repeated five times for each comparison.

Effect of removing glume Gl on egg laying and grain damage

During the 1986 rainy season at Kamboinse, Burkina Faso, the role of glumes in head bug resistance was studied by removing glume $\mathrm{Gl}$ from seeds of $\mathrm{S} 29$ at the milk stage with a pair of forceps. Glume $\mathrm{Gl}$ was removed from all spikelets of five randomly marked panicles having five primary branches. This cultivar has long glumes, and the grains are covered by the glumes for up to 20 days after anthesis. The removal of glume $\mathrm{Gl}$ exposed the developing grain for feeding and oviposition. Five panicles of SPV 35 with exposed grain, but of the same age after anthesis, served as an undisturbed control. The panicles were infested with live pairs of bugs under a headcage. Data were recorded on feeding punctures and eggs laid/I(X) grains sampled at randon 10 days after infestation. During the 1988 rainy season, the experiment was repeated on another guinense' cultivar. CSM 388 at Sotuba, Mali. Observations on feeding punctures and egg laying were recorded on 25 grains sampled at random.

\section{Role of panicle and glume charac teristic s in resistunce' w) head bugs.}

Panicle and glume characteristics were evaluated in 11 genotypes during the 1985 rainy season at Sotuba, Mali. Data were recorded on number of days required for glume opening, glume length, glume hairiness, glume covering of the grain, and panicle compactness. Days to glume opening were recorded by tagging three branches in three panicles in a genotype at anthesis. The number of days required for the grain to be visible outside the glumes was recorded as the period for glume opening. Glume length and breadth were recorded in mm in 10 spikelets sampled at random. Samples were drawn from five panicles at anthesis and three branches were sampled from each panicle. Glume covering of the grain was evaluated visually on a 1 to 5 scale $(1=<20 \%$ grain surface covered by the glumes; and $5=>60 \%$ grain surface covered by the glumes). Glume hairiness was 
rated on a 1 to $3^{\circ}$ scale $(1=$ glume shining and without hairs; and 3 = glume completely covered with long hairs) under a microscope ( $x 40)$. Panicle compactness was evaluated on a 1 to 3 scale ( $1=$ compact, $2=$ semicompact, and $3=$ loose). Data on panicle compactness and glume length was also recorded in genotypes screened under headcage during 1986 in Burkina Faso, and during 1988 in Mali.

\section{Statistical analysis}

Data on bug numbers were converted to square root values, and were subjected to analysis of variance to test the significance of difference between treatment effects. Treatment means were compared by the least significant difference (LSD). Association of head bug numbers and grain damage with panicle, and glume characteristics was determined through correlation analysis.

\section{RESULTS}

\section{Screening for resistance}

Head bug numbers were significantly lower at the milk stage in IS 14332, CSM 388, Malisor 84-7, 83F6-16, 83F6-148, and 83F6-87 as compared to A 13120 and E 35-1; of which IS 14332, CSM 388, Malisor 84-7, and 83F6-87 suffered lower grain damage than 83F6-16 and 83F6-148 (Table 1). IS
14332, CSM 388, E 35-1, 83F6-87, and ICSV 197 were also less damaged by grain moulds (damage

Table 1. Head bug numbers and grain damage in 11 sorghum cultivars under natural infestation (1985 rainy season, Mali)

\begin{tabular}{lccc}
\hline Cultivar & $\begin{array}{c}\text { No. of head } \\
\text { bugs/panicle }\end{array}$ & $\begin{array}{c}\text { Grain } \\
\text { damage }\end{array}$ & $\begin{array}{c}\text { Grain mould } \\
\text { severity }\end{array}$ \\
\hline IS 14332 & $5^{*}(2.1)^{+} \mathrm{a}$ & $1.1^{\ddagger} \mathrm{ab}$ & $1.0 \mathrm{a}$ \\
CSM 388 & $9(2.7) \mathrm{ab}$ & $1.0 \mathrm{a}$ & $1.0 \mathrm{a}$ \\
Malisor $84-7$ & $20(4.2) \mathrm{bc}$ & $1.4 \mathrm{~b}$ & $2.1 \mathrm{c}$ \\
$83 F 6-87$ & $26(4.8) \mathrm{cd}$ & $2.2 \mathrm{c}$ & $1.6 \mathrm{~b}$ \\
A 13120 & $62(7.7) \mathrm{g}$ & $2.4 \mathrm{~cd}$ & $1.8 \mathrm{bc}$ \\
$83 \mathrm{~F} 6-111$ & $45(6.6) \mathrm{e}$ & $2.6 \mathrm{de}$ & $2.6 \mathrm{de}$ \\
ICSV 197 & $49(6.5) \mathrm{f}$ & $2.8 \mathrm{ef}$ & $1.6 \mathrm{~b}$ \\
E 35-1 & $100(9.8) \mathrm{h}$ & $3.0 \mathrm{~g}$ & $1.0 \mathrm{a}$ \\
$83 F 6-16$ & $27(4.3) \mathrm{cd}$ & $3.0 \mathrm{~g}$ & $2.8 \mathrm{e}$ \\
$83 F 6-42$ & $38(5.8) \mathrm{def}$ & $4.4 \mathrm{~g}$ & $2.2 \mathrm{~cd}$ \\
$83 F 6-148$ & $39(6.2) \mathrm{def}$ & $4.4 \mathrm{~g}$ & $2.8 \mathrm{e}$ \\
SE \pm & 1.89 & 0.12 & 0.13 \\
LSD at 5\% & 2.67 & 0.35 & 0.37 \\
\hline
\end{tabular}

${ }^{*}$ Grain mould severity $(1=<10 \%, 2=11-25 \%, 3=26-$ $40 \%, 4=41-60 \%$, and $5=>60 \%$ mould infected grains).

${ }^{+}$Figures in parentheses are square root transformed values. Figures followed by the same letter within a column are not significantly different at $P<0.05$.

$\neq$ Grain damage rating $(1=$ grain with a few feeding punctures, $2=$ grain with feeding punctures and $10 \%$ grain with eggs, $3=$ grain slightly tanned and $25 \%$ grains with eggs, 4 = grain slightly shrivelled and $50 \%$ grains with eggs, and $5=$ grain showing $>60 \%$ shrivelling and $>60 \%$ grains with eggs).

Table 2. Head bug numbers in 11 sorghum cultivars infestec with 20 pairs of bugs/panicle under headcage and their panicle and glume characteristics (1985 rainy season, Sotuba, Mali)

\begin{tabular}{|c|c|c|c|c|c|c|c|c|}
\hline \multirow[b]{2}{*}{ Cultivar } & \multirow{2}{*}{$\begin{array}{l}\text { No. of head } \\
\text { bugs/panicle }\end{array}$} & \multirow{2}{*}{$\begin{array}{l}\text { Grain* } \\
\text { damage }\end{array}$} & \multirow{2}{*}{$\begin{array}{l}\text { Panicle } \\
\text { type }^{* *}\end{array}$} & \multirow{2}{*}{$\begin{array}{c}\text { Days to glume } \\
\text { opening }\end{array}$} & \multicolumn{2}{|c|}{ Slume length (mm) } & \multirow{2}{*}{$\begin{array}{c}\text { Glume } \\
\text { hairiness }\end{array}$} & \multirow{2}{*}{$\begin{array}{c}\text { Glume } \\
\text { covering }\end{array}$} \\
\hline & & & & & GI & $\mathrm{G} 2$ & & \\
\hline IS 14332 & $56(7.5)^{\neq a}$ & $1.0 \mathrm{a}^{* * *}$ & 1 & 23 & $5.9 \mathrm{~h}$ & $5.9 \mathrm{~h}$ & $1.7 \mathrm{~d}$ & $2.8 \mathrm{f}$ \\
\hline CSM 388 & $118(10.7) a b$ & $1.0 \mathrm{a}$ & 1 & 20 & $5.1 \mathrm{~g}$ & $5.3 \mathrm{f}$ & $0.7 \mathrm{a}$ & $2.3 \mathrm{e}$ \\
\hline Malisor 84-7 & $78(8.2) a b$ & $2.0 \mathrm{~b}$ & 3 & 8 & $4.3 \mathrm{e}$ & $4.2 \mathrm{c}$ & $2.1 \mathrm{f}$ & $2.1 \mathrm{~d}$ \\
\hline $83 F 6-87$ & $95(9.6) a b$ & $3.0 \mathrm{c}$ & 1 & 16 & $5.1 \mathrm{~g}$ & $5.0 \mathrm{e}$ & $2.1 \mathrm{f}$ & $2.0 \mathrm{~d}$ \\
\hline $83 F 6-16$ & $186(13.4) a b$ & $4.0 \mathrm{e}$ & 3 & 6 & $4.5 \mathrm{f}$ & $4.7 \mathrm{~d}$ & $1.5 \mathrm{e}$ & $1.5 \mathrm{c}$ \\
\hline $83 F 6-42$ & $262(15.9) b$ & $3.5 \mathrm{~d}$ & 1 & 8 & $3.6 \mathrm{~b}$ & $3.8 \mathrm{~b}$ & $1.9 \mathrm{e}$ & $1.3 \mathrm{~b}$ \\
\hline $83 F 6-148$ & $165(12.4) a b$ & $4.0 \mathrm{e}$ & 2 & 7 & $3.8 \mathrm{c}$ & $3.9 \mathrm{~b}$ & $2.8 \mathrm{~g}$ & $1.6 \mathrm{c}$ \\
\hline $83 F 6-111$ & $131(11.1) \mathrm{ab}$ & $3.0 \mathrm{c}$ & 2 & 14 & $5.8 \mathrm{~h}$ & $5.6 \mathrm{~g}$ & $1.2 \mathrm{~b}$ & $2.4 \mathrm{e}$ \\
\hline ICSV 197 & $101(10.1) a b$ & $3.0 \mathrm{c}$ & 2 & 7 & $3.4 \mathrm{a}$ & $3.4 \mathrm{a}$ & $1.2 \mathrm{~b}$ & $1.2 \mathrm{~b}$ \\
\hline A 13120 & $182(12.9) \mathrm{ab}$ & $2.0 \mathrm{~b}$ & 2 & 8 & $4.0 \mathrm{~d}$ & $3.9 \mathrm{~b}$ & $1.3 \mathrm{~b}$ & $1.2 \mathrm{~b}$ \\
\hline E 35-1 & $175(13.0) a b$ & $3.0 \mathrm{c}$ & 3 & 8 & $4.6 \mathrm{f}$ & $4.3 \mathrm{c}$ & $1.3 \mathrm{~b}$ & $0.7 \mathrm{a}$ \\
\hline SE \pm & 2.93 & 0.14 & & & 0.04 & 0.06 & 0.03 & 0.02 \\
\hline LSD at $5 \%$ & 8.10 & 0.39 & & & 0.12 & 0.18 & 0.09 & 0.06 \\
\hline
\end{tabular}

*Grain damage see Table 1.

** Panicle compactness $(1=$ loose, 2 = semi-compact and $3=$ compact $)$.

+ Number of days for grain to be visible outside the glume.

${ }^{+}$Glume hairiness (1=glume slightly hairy, 2=glume medium hairy and 3=glume highly hairy).

F Glume covering ( $1=30 \%$ grain surface covered by glumes, $2=50 \%$ grain surface covered by glumes, and $3=75 \%$ grain surface covered by glumes).

\#Figures in parentheses are square root transformed values.

*** Figures followed by the same letter within a column are not significantly different at $P<0.05$. 
Table 3. Effect of head bug feeding on grain weight/panicle, 1000 grain weight. and grain hardness in 11 sorghum cultivars infested with 20 bug pairs/panicle under headcage conditions (1985 rainy season. Sotuba. Mali)

\begin{tabular}{|c|c|c|c|c|c|c|c|}
\hline \multirow[b]{2}{*}{ Cultivar } & \multicolumn{2}{|c|}{ Grain weight/panicle (g) } & \multirow{2}{*}{ light grain } & \multicolumn{2}{|c|}{1000 grain weight $(g)$} & \multicolumn{2}{|c|}{ Grain hardness } \\
\hline & Heavy grain & Light grain & & Heavy grain & Light grain & Heavy grain & Light grain \\
\hline IS 14334 & $22.3 \mathrm{~b}$ & $1.0 \mathrm{a}$ & 4.3 & $14.0 \mathrm{a}$ & $12.0 \mathrm{a}$ & $2.2 \mathrm{a}$ & $2.5 \mathrm{a}$ \\
\hline CSM 388 & $31.7 \mathrm{c}$ & $5.0 \mathrm{ab}$ & 13.6 & $22.5 \mathrm{e}$ & $15.6 \mathrm{~b}$ & $2.8 \mathrm{~b}$ & $3.5 \mathrm{~b}$ \\
\hline $83 F 6-87$ & $19.2 \mathrm{~b}$ & $11.7 \mathrm{~cd}$ & 26.3 & $25.8 \mathrm{~g}$ & $23.0 \mathrm{e}$ & $3.1 \mathrm{bc}$ & $3.8 \mathrm{~b}$ \\
\hline $83 F 6-148$ & $12.8 \mathrm{a}$ & $32.7 \mathrm{f}$ & 75.8 & $22.3 \mathrm{e}$ & $19.3 \mathrm{~d}$ & $3.1 \mathrm{bc}$ & $3.8 \mathrm{~b}$ \\
\hline Malisor 84-7 & $34.9 \mathrm{c}$ & $6.1 \mathrm{abc}$ & 14.8 & $19.4 \mathrm{c}$ & $1.3 .2 \mathrm{a}$ & 3.4 de & $4.0 \mathrm{c}$ \\
\hline A 13120 & $32.9 \mathrm{c}$ & $11.7 \mathrm{~cd}$ & 26.3 & 21.7 de & $15.3 \mathrm{~b}$ & $3.2 \mathrm{~cd}$ & $4.0 \mathrm{c}$ \\
\hline ICSV 197 & $39.9 \mathrm{~d}$ & $9.0 \mathrm{bcd}$ & 18.5 & $17.6 \mathrm{~b}$ & $12.4 \mathrm{a}$ & $3.0 \mathrm{bc}$ & $4.6 \mathrm{~d}$ \\
\hline $83 F 6-16$ & $22.4 \mathrm{~b}$ & $14.2 \mathrm{~d}$ & 38.8 & $23.5 \mathrm{f}$ & $19.9 \mathrm{~d}$ & $3.9 \mathrm{f}$ & $4.6 \mathrm{~d}$ \\
\hline E 35-1 & $22.1 \mathrm{~b}$ & $14.6 \mathrm{~d}$ & 39.8 & $26.9 \mathrm{~h}$ & $22.2 \mathrm{e}$ & $3.6 \mathrm{ef}$ & $4.8 \mathrm{~d}$ \\
\hline $83 F 6-42$ & $10.9 a$ & $26.8 \mathrm{e}$ & 70.8 & $21.2 \mathrm{~d}$ & $17.0 \mathrm{c}$ & $3.5 \mathrm{de}$ & $4.8 \mathrm{~d}$ \\
\hline $83 F 6-111$ & $12.8 \mathrm{a}$ & $32.7 \mathrm{f}$ & 75.8 & $26.0 \mathrm{gh}$ & $20.8 \mathrm{~d}$ & $3.4 \mathrm{de}$ & $5.4 \mathrm{e}$ \\
\hline SE \pm & 2.22 & 1.99 & - & 0.30 & 0.43 & 0.10 & 0.16 \\
\hline LSD at $5 \%$ & 6.27 & 5.62 & - & 0.83 & 1.22 & 0.28 & 0.45 \\
\hline
\end{tabular}

Figures followed by the same letter within a column are not significantly different at $P<0.05$.

Table 4. Food quality of 11 sorghum cultivars infested with 20 pairs of head bugs/panicle under headcage ( 1985 rainy season, Sotuba, Mali)

\begin{tabular}{lcclll}
\hline & "To" keeping quality & & \multicolumn{2}{c}{ "To" colour ${ }^{+}$} \\
\cline { 2 - 3 } Cultivar & $\begin{array}{c}\text { Heavy } \\
\text { grain }\end{array}$ & $\begin{array}{l}\text { Light } \\
\text { grain }\end{array}$ & & $\begin{array}{l}\text { Heavy } \\
\text { grain }\end{array}$ & $\begin{array}{l}\text { Light } \\
\text { grain }\end{array}$ \\
\hline 83 F6-16 & 2.3 & 4.5 & Dark red & Dusky red \\
83 F6-87 & 3.0 & 4.0 & Dark brown & Dusky red \\
E 35-1 & 3.3 & 5.0 & Light olive brown & Light olive brown \\
83 F6-148 & 4.0 & 4.3 & Dark grayish brown & Black \\
83 F6-42 & 4.0 & 5.0 & Light olive brown & Dark red \\
A 13120 & 3.5 & 4.3 & Dark yellowish brown & Light yellowish brown \\
83 F6-111 & 3.6 & 4.0 & Dark reddish brown & Dusky red \\
Malisor 84-7 & 1.3 & 4.5 & Light olive brown & Dark brown \\
ICSV 197 & 2.3 & 4.0 & Light olive brown & Olive brown \\
CSM 388 & 2.6 & 3.0 & Dark yellowish & Dark brown \\
IS 14332 & 1.0 & - & Olive & - \\
\hline
\end{tabular}

\footnotetext{
* Scores above 3 indicate poor food quality.

+ According to Munsell soil colour chart.
}

rating, DR < 1.6). ExceptE35-1 and 83F6-83, cultivars susceptible to head bugs also suffered a greater incidence of grain moulds.

Under no-choice conditions in the headcage, the bug population increase was high (Table 2). 83F6-42 had significantly greater number of bugs than the other genotypes tested. Head bug numbers were $<100$ /panicle in IS 14332, Malisor 84-7, and 83F687. IS 14332, CSM 388, A 13120, and Malisor 84-7 suffered lower DR $<2.0$ compared with $83 \mathrm{~F} 6-16$ and 83F6-148 with $D R=4$. These cultivars were also less susceptible to bugs under natural conditions. However, 83F6-16 and 83F6-148 had low bug numbers under natural infestation, but were highly susceptible under headcage screening.

The percentage of light grain was lower in IS 14332, CSM 388, and Malisor 84-7 when infested with 20 pairs of bugs/panicle in the headcage (Table 3). $83 \mathrm{~F} 6-42$ and $83 \mathrm{~F} 6-148 \mathrm{had}>70 \%$ light grain and suffered greater bug damage $(D R=4)$. Differences in 1000 grain weight were also less between the heavy and light grain fractions in IS 14332, 83F6-87, 83F6148, 83F6-16 and E 35-1, of which the last three genotypes had a damage rating of 3.5. These differences in visual damage rating and 1000 grain weight may be because of genotypic differences in tanning caused by bug feeding and oviposition. Nontan genotypes show red-brown feeding spots while in the tan genotypes, the feeding spots are light-brown and this may affect visual rating of grain for head bug damage. Grain hardness for heavy grain was higher (score < 3.1) in IS 14332, CSM 388, 83F6-87, 83F6148, and ICSV 197 compared with 83F6-16. Only IS 14332 had an acceptable grain hardness rating for the light grain fraction.

Food quality ("to" quality) was acceptable for heavy grain (score <3) in 83F6-16, 83F6-87, Malisor 84-7, ICSV. 197, CSM 388, and IS 14332 (Table 4). 
Table 7. Population increase of $E$. immac ulatus on three sorghum cultivars under headcage ( 20 pairs/panicle) (Kamboinse. Burkina Faso, 1986)

\begin{tabular}{|c|c|c|c|c|c|c|}
\hline \multirow[b]{2}{*}{ Cultivar } & \multicolumn{3}{|c|}{ No. of head bugs/panicle } & \multirow{2}{*}{$\begin{array}{c}\text { Damage } \\
\text { rating }\end{array}$} & \multirow{2}{*}{$\begin{array}{c}\text { Panicle } \\
\text { type }\end{array}$} & \multirow{2}{*}{$\begin{array}{l}\text { Glume } \\
\text { length } \\
(\mathrm{mm})\end{array}$} \\
\hline & Adults & Nymphs & Total & & & \\
\hline $\begin{array}{l}\text { Kamboinse } \\
\text { local }\end{array}$ & $40(6.2)^{* *} \mathrm{at}$ & $1(0.7) \mathrm{a}$ & $41(6.4) \mathrm{a}$ & $1.4 \mathrm{a}$ & 1 & $7.0 \mathrm{c}$ \\
\hline S 29 & $38(6.2) \mathrm{a}$ & $4(1.7) b$ & $42(6.5$ & 1.2 & 1 & $6.4 \mathrm{~b}$ \\
\hline SPV 35 & $40(6.3) \mathrm{a}$ & $46(6.8) \mathrm{c}$ & $86(9.3) b$ & $4.0 \mathrm{~b}$ & 3 & $4.0 \mathrm{a}$ \\
\hline & $\pm(0.09)$ & $\pm(C$ & $\pm(0$. & \pm 0.24 & - & \pm 0.11 \\
\hline LSD at $5 \%$ & $(0.27)$ & $(0.80)$ & $(0.58)$ & 0.74 & - & 0.34 \\
\hline
\end{tabular}

${ }^{*}$ Panicle type $(1=$ loose, 2 = semi-compact and $3=$ compact $)$.

${ }^{* *}$ Figures in parentheses are square root transformed values.

${ }^{+}$Figures followed by the same letter within a column are not significantly different at $P<0.05$.

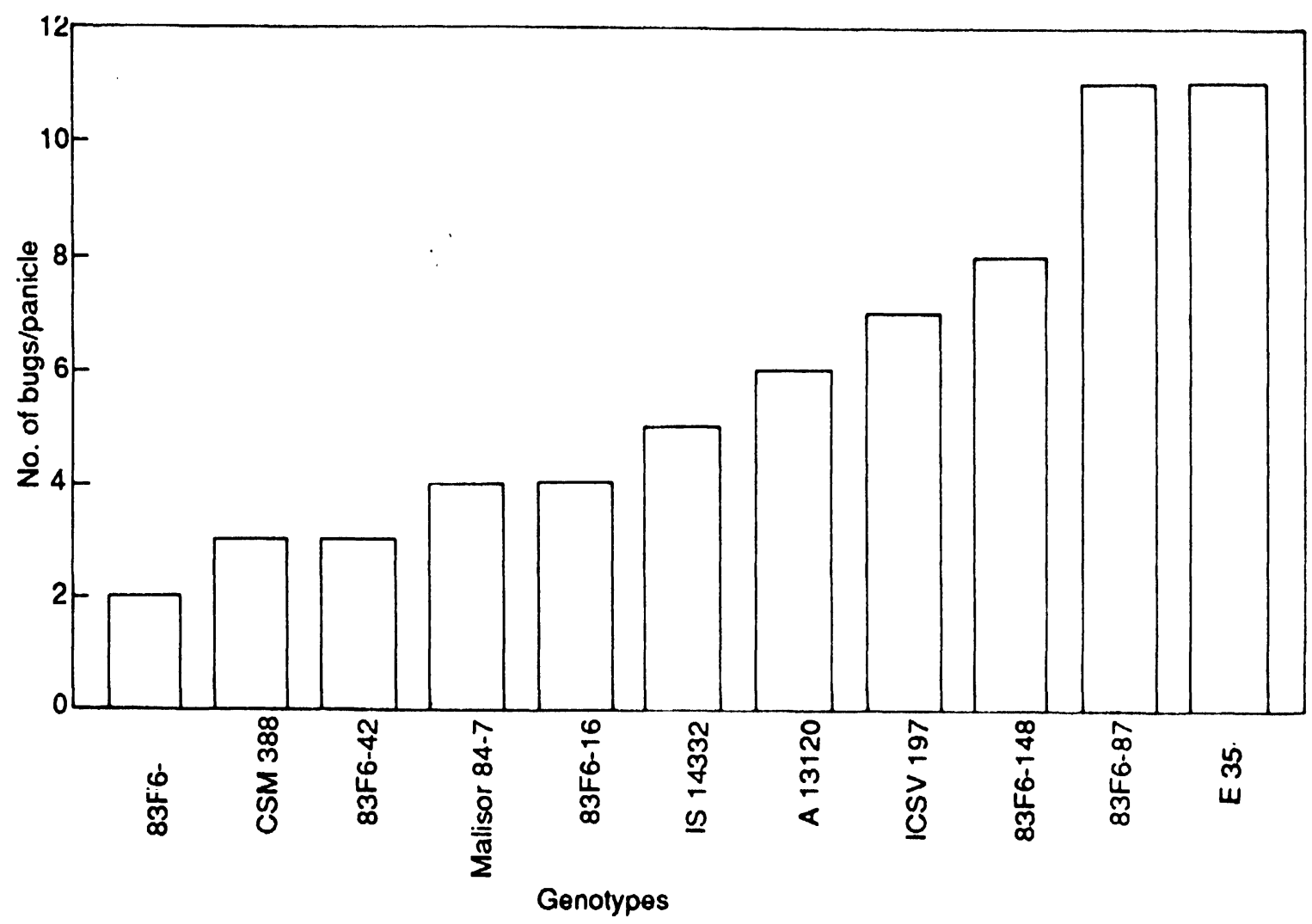

Fig. 2. Cultivar non-preference of 11 sorghum genotypes to head bugs at the complete-anthesis stage under field conditions.

\section{Mechanisms of resistance}

Host plant preference. Under field conditions, IS 14332, CSM 388, Malisor 84-7, 83F6-16 and 83F6111 had < five females/panicle at the completeanthesis stage compared with 11 females on E 35-1 (Fig. 2). Most of the bugs found at this stage were females. These genotypes also had fewer head bugs at the dough stage (Table 1). Thus, cultivar nonpreference at the initial stages seems to be an important factor in determining bug population increase and

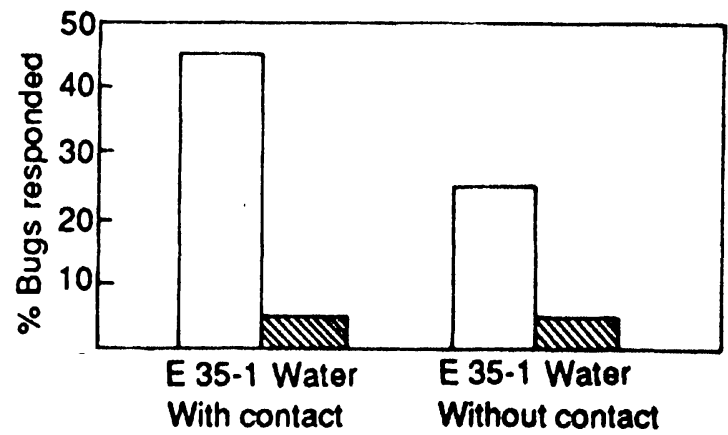

Fig. 3. Relative preference of milk grain and water to head bugs. 


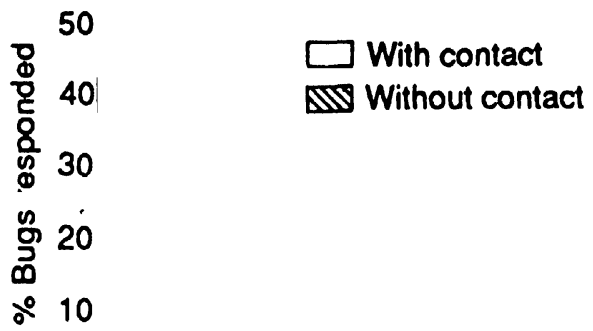

\section{F6-111 E 35-1 CSM 388}

Fig. 4. Cultivar non-preference to sorghum head bugs with and without contact with the host plant.

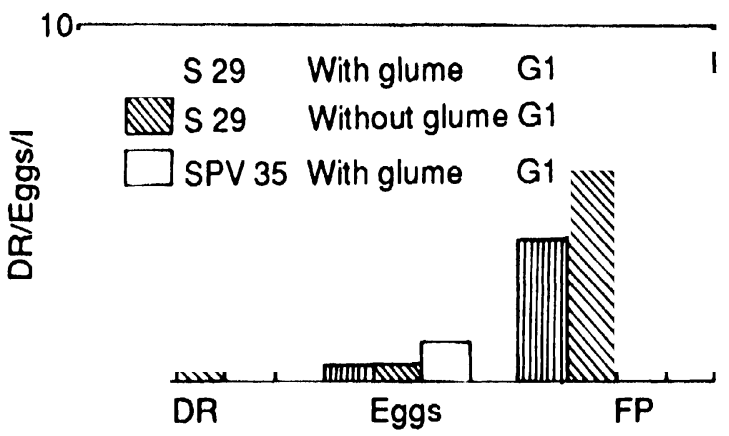

Fig. 5. Effect of removing glume $\mathrm{Gl}$ on feeding and oviposition by the head bugs ( $D R=$ damage rating, eggs $=$ eggs $/ 10$ grains, and FP = number of feeding punctures).

grain damage in different genotypes under natural infestation. CSM 388 was less preferred by the bugs than E 35-1 in olfactometer tests (Fig. 3). Differences in cultivar preference were reduced when the bugs

Table 8. Correlation coefficients between head bug numbers, grain damage, and panicle and glume characteristics

\begin{tabular}{|c|c|c|c|c|}
\hline \multirow{2}{*}{$\begin{array}{l}\text { Glume/ } \\
\text { panicle } \\
\text { character }\end{array}$} & \multicolumn{2}{|c|}{ Head bug numbers } & \multicolumn{2}{|c|}{ Damage rating } \\
\hline & $\begin{array}{c}\text { Natural } \\
\text { conditions }\end{array}$ & $\begin{array}{l}\text { Headcage } \\
\text { conditions }\end{array}$ & $\begin{array}{c}\text { Natural } \\
\text { conditions }\end{array}$ & $\begin{array}{l}\text { Headcage } \\
\text { conditions }\end{array}$ \\
\hline $\begin{array}{l}\text { Panicle } \\
\text { compactne }\end{array}$ & ness 0.45 & $0.72^{*}$ & $0.60^{*}$ & 0.55 \\
\hline $\begin{array}{l}\text { Days to glu } \\
\text { opening }\end{array}$ & $\begin{array}{l}\text { ume } \\
-0.55\end{array}$ & $-0.72^{*}$ & $-0.82^{* *}$ & $-0.73^{* *}$ \\
\hline $\begin{array}{l}\text { Glume } \\
\text { length GI }\end{array}$ & $1 \quad-0.38$ & -0.42 & $-0.60^{*}$ & -0.42 \\
\hline $\begin{array}{l}\text { Glume } \\
\text { length G2 }\end{array}$ & -0.52 & -0.35 & $-0.60^{*}$ & -0.41 \\
\hline $\begin{array}{l}\text { Glume } \\
\text { hairines. } \\
\text { Glume }\end{array}$ & 0.09 & 0.07 & 0.19 & 0.44 \\
\hline covering & $-0.83^{* *}$ & -0.56 & $-0.67^{*}$ & -0.52 \\
\hline
\end{tabular}

$*^{* * * *}=$ Significant at $P=0.05$ and 0.01 , respectively.

were not allowed a contact with the host plant (Fig. 4). Therefore, both contact and odour stimuli seem to determine host plant selection and acceptance by $E$. immaculatus.

Effect of removing glume GI on feeding and oviposition in guinense sorghums. During the 1986 season, removal of glume Gl in S29 (a less susceptible guinense cultivar) did not affect the number of eggs laid, but the number of feeding punctures and grain damage increased substantially (Fig. 5).

Association of panicle and glume characteristics with resistance to head bugs. Head bug resistant genotypes (IS 14332, CSM 388, 83F6-87) took longer period for glume opening, had longer glumes ( $>5$ $\mathrm{mm}$ ), and $>50 \%$ of the grain surface was covered by the glumes (Table 2). Malisor 84-7, though less susceptible to bugs than E 35-1, had medium sized glumes. However, it has a very hard corneous grain. Genotypes with shorter glumes were generally more susceptible to bugs. 83F6-111 and 83F6-16 had medium sized glumes and suffered moderate levels of bug damage. These genotypes required about 2 weeks for glume opening. Genotypes with loose to semi-compact panicles were less susceptible to bugs (Table 2). Kamboinse local, S 29, CSM 388 and Sakoika, which were less susceptible to the head bugs, had longer glumes than the susceptible checks SPV 35 and S 34 (Tables 5 and 7). Panicle compactness was positively associated with head bug numbers (Table 8). Days to glume opening, glume length, and glume covering of the grain were negatively associated with head bug numbers and grain damage.

\section{DISCUSSION}

Mirid head bugs are one of the most important factors limiting sorghum production in the semi-arid tropics (Sharma and Lopez, 1990a; Steck et al., 1989; McFarlane, 1989). Head bug damage also spoils the grain quality and renders it unfit for human consumption (Sharma and Lopez,1989; Sharma et al., 1992). E. immaculatus lays eggs inside the grain, which results in decomposition of the grain at the site of oviposition. Bug damaged grain also shows greater severity of mould incidence (Sharma et al., 1992). Thus, it is very important to identify sources of resistance to this insect and identify the factors associated with resistance in order to transfer resistance into improved high yielding cultivars.

Screening for resistance can be carried out by using infester row and headcage techniques (Sharma and Lopez, 1992a; Sharma et al., 1992). Identified sources of resistance should be tested across seasons and/or locations to identify genotypes with stable resistance (Sharma and Lopez, 1991). The present studies indicate that guinense land races with a greater covering of the grain by the glumes and having hard corneous grain are resistant to the head bugs.

Cultivar differences in susceptibility to $E$. immaculatus were evident both under natural and headcage conditions. Guinense land races with long glumes (traditionally cultivated in the guinean zone) (CSM 388,Sakoika, and IS 14332), were less damaged 
by head bugs than $\mathrm{S} 34$ and E 35-1. Many germplasm accessions of guinense origin have earlier been identified to be resistant to another mirid bug, Calocoris angustatus Leth. (Sharma and Lopez, 1992b). Malisor 84-7 derived from guinense sorghums, is of medium height, has a hard comeous grain, and is relatively resistant to head bug damage. It can be growr in head bug endemic areas, and used in breeding for resistance to head bugs.

Feeding and oviposition by the head bugs decreased 1000 grain weight, increased the percentage of light grain, decreased grain hardness, and rendered the grain unfit for food. Even low levels of head bug damage could render the grain unfit for human consumption. Similar effects of head bug damage on sorghum grain have been reported for $C$. angustatus (Sharma and Lopez, 1989). Since genotypes with a hard corneous grain are a prerequisite for food in West Africa (Da et al., 1982), breeding for resistance to head bugs should be one of the most important components for sorghum improvement.

Cultivar non preference by the adults at the milk stage is one of the mechanisms of resistance to head bugs. At this stage, the adults select their host plant for feeding and oviposition. Genotypic differences in relative preference by the bugs were observed both under field and laboratory conditions. However, both odour and contact stimuli were important in host selection since differences between genotypes were reduced when the bugs were not allowed contact with the host plant. Cultivar nonpreference has also been observed to influence host plant selection by $C$. angustatus (Sharma and Lopez, 1990b).

Genotypes with compact panicles provide a safe niche for the development and multiplication of bugs (Sharma, 1985), although genotypes with compact panicles may not necessarily be susceptible, e.g. Malisor 84-7 has a compact panicle, but was less susceptible to the bugs. On the other hand, genotypes with loose panicles may also be highly susceptible, e.g. 83 F6-42, 83 F6-148 and A 13120. Some of these interactions are highly influenced by the glume and grain characteristics of different genotypes (Sharma, 1985). Days to glume opening appeared to be associated with genotypic resistance to head bugs. This is because of the fact that head bug feeding and oviposition were confined to the grain surface not covered by the glumes. Cultivars with more than 20 days to glume opening (e.g., IS 14332 and CSM 388) were resistant to the bugs. In cultivars with a longer period required for glume opening, the grain becomes relatively harder for feeding and oviposition when it becomes visible outside the glumes. 83 F6-87 and 83 F6-111 took about 2 weeks to glume opening and suffered moderate levels of grain damage. Malisor
84-7 does not have the above characteristics, but it is less susceptible because of faster grain hardening and has a highly corneous grain on which feeding and oviposition may be difficult.

Several lines identified to be resistant to $E$. immaculatus (CSM 388. Malisor 84-7. Sakoika, S 29 and Kamboinse Local) can be used in a resistance breeding programme to develop head bug resistant high yielding cultivars. Greater covering of the grain by the glumes. days to glume opening. grain hardness and quicker grain maturity. can be used as marker traits to select for resistance to head bugs.

Acknowledgements-We thank Drs S. V. R. Shetty. C. M. Pattanayak and D. S. Murty for their help in carrying out these studies. We also thank Drs. J. M. J. de Wet and Dr. K. F. Nwanze for their comments on the manuscript, Mr. Lassine Dembele and 1. Tereta for their help in these experiments, and Mr. I. Krishna Murthy for typing the manuscript.

Approved as joumal article No. 1073 by the International Crops Research Institute for the SemiArid Tropics (ICRISAT).

\section{REFERENCES}

Da S., Akingabala J. O., Rooncy I. W., Scheuring J. F. and Miller F. R. (1982) Evaluation of " 10 " quality in a sorghum breeding program. Proceedings, International Symposium on Sorghum Grain Quality, 28-31 Oct. 1981, ICRISAT Centre, India. International Crops Research Institute for the Semi-Arid Tropics (ICRISAT) India, pp. 11-23.

Doumbia Y. O. and Bonzi S. M. (1985) Note sur le problems les insectes de la panicule du sorgho au Mali. Paper presented at the West African Sorghum Network Workshop, 22-24 Oct, 1985. Institut d'Economie Rurale, Bamako, Mali.

Hallgren L. and Murty D. S. (1983) A screening test for grain hardness in sorghum employing density grading in sodium nitrate solution. J. Sci. 1, 265274.

McFarlane J. H. (1989) The hemipterous insects and spiders of sorghum panicles in Northern Nigeria. Insect Sci. Applic. 10, 277-284.

Nwanze K. F. (1985) Sorghum insect pests in West Africa. Proceedings, International Sorghum Entomology Workshop, 15-21 July 1984. Texas A \& M University, Tx., USA. International Crops Research Institute for the Semi-Arid Tropics (ICRISAT), India, pp. 37-43.

Sharma H. C. (1985) Screening for host-plant resistance to mirid head bugs. In Proceedings, International Sorghum Entomolgy Workshop, 15- 
21 July 1984, Texas A \& M University, College Station, Tx, USA. International Crops Research Institute for the Semi-Arid Tropics (ICRISAT), India, pp. 317-336.

Sharma H. C. and Lopez V. F. (1989) Assessment of avoidable losses and economic injury levels for the sorghum head bug, Calocoris angustatus Leth. (Hemiptera: Miridae). Crop Prot. 8, 429435.

Sharma H. C. and Lopez V. F. (1990a) Biology and population dynamics of sorghum head bugs (Hemiptera: Miridae). Crop Prot. 9, 164-173.

Sharma H. C. and Lopez V. F. (1990b) Mechanisms of resistance in sorghum to head bug, Calocoris angustatus. Entomol. exp. appl. 57, 285-294.

Sharma H. C. and Lopez V. F. (1991) Stability of resistance in sorghum to Calocoris angustatus
(Hemiptera: Miridae).J.Econ.Entomol.84. 10881094.

Sharma H. C. and Lopez V. F. (1992a) Screening for plant resistance to sorghum head bug. Culecoris angustatus Leth. Insect Sci. Applic. 13, 315-325.

Sharma H. C. and Lopez V. F. (1992b) Genotypic resistance in sorghum to head bug. Calocoris angustatus. Euphytica. 58, 193-20().

Sharma H. C., Doumbia Y. O. and Dioriso N. Y. (1992) A headcage technique to screen for resistance to mirid head bug. Eurvistyluss immaculatus Odh. in West Africa. Insect Sci. Applic. 13, 417-427.

Steck G. J., Teetes G. L. and Maiga S. D. (1989) Species composition and injury to sorghum by panicle feeding bugs in Niger. Insect Sci. Applic. 10, 199-217. 